\title{
Moroccan Women in Madrid. Between Change and Continuity
}

\author{
Christof Van Mol*
}

\begin{abstract}
This article focuses on individual migration and acculturation processes experienced by Moroccan women in the area of Madrid, based on qualitative research conducted in the Spanish capital in 2008. The results show that Moroccan women restructure their daily practices through complex acculturation processes, orienting them towards both the society of origin and that of arrival. They experience a constant struggle in getting to know the traditions of Spanish society, reorienting their former traditions and inventing new solutions. Moroccan women develop new ways of adapting themselves to their situation in Madrid. This acculturation process bridges the continuity with their culture of origin and reflects changes related to the new context. The studied women move in a transnational space with rigid borders, which is intersected by several social categories such as their education, ethnicity and gender, influencing their relative position within this space.
\end{abstract}

Keywords: migration; acculturation; transnationalism; Spain; Morocco; Europe

* Netherlands Interdisciplinary Demographic Institute (NIDI) / KNAW / UG. mol@nidi.nl 


\section{Introduction}

Since the 1980s, scholars such as Morokvasic (1984) have been criticising the lack of studies that focus on women's migration. Recently, a whole spectrum of research has begun focusing on the contribution of women migrants to the labour force in Europe, and the intersection of gender, ethnicity, class and education in the production of multiple different consequences in their lives (Salih, $2003: 26)$. In contrast to scholarship that regards migration as a gender-neutral process, movement across and within borders should be conceived as a gendered process. For example, the conditions for participating in international movements might not always exist for women, and they may hold a different citizenship status, since in some countries citizenship is primarily a masculine set of rights and responsibilities (Salih, 2003; Joseph, 2000). Moreover, female-specific migration flows exist, and in certain labour niches such as the care and catering sector, women may encounter fewer problems in finding a job compared to men. Similarly, acculturation processes can also be conceived as gendered, as migrant men and women might occupy diverse positions in the countries of origin and of arrival, due to differences in status and position within the family, society, and religion (Nyhagen-Predelli, 2004).

In this article, I examine the migration and acculturation processes experienced by Moroccan women in the area of Madrid. The Moroccan community is

* Netherlands Interdisciplinary Demographic Institute (NIDI) / KNAW / UG. mol@nidi.nl 
the largest foreign community in Spain today. However, the presence of women is quite a new trend. Although there are similarities between Moroccan and Spanish culture that are due to the political, economic, cultural and social contact over the centuries, Moroccan women relocating to Spain encounter significant challenges. The focus on Madrid is informed by historic and contemporary migration patterns. The Spanish capital is a major attraction for foreign female migration flows, since women can easily find work in the care and food service industries, which are the region's principal labour niches (Soriano Miras, 2006). There are about 33,000 Moroccan female migrants living in the Madrid metropolitan area, a city of 6.2 million people, and Moroccan women constitute $40 \%$ of the total Moroccan population in the city (Dié et al., 2009; own calculations). In this paper, I specifically focus on the acculturation processes experienced by Moroccan women who came to Spain to join their family.

Through in-depth interviews and unobtrusive observation of such women in the Madrid metropolitan area, I provide rich and nuanced insight into individually experienced migration and acculturation processes. Through an explicit focus on individual experiences, rather than the aggregate group level, I aim to contribute to the existing literature in three ways. First, instead of considering these women merely as following their husbands, I highlight how these women are active agents throughout the migration and acculturation process, making autonomous decisions. Second, I

* Netherlands Interdisciplinary Demographic Institute (NIDI) / KNAW / UG. mol@nidi.nl 
frame their individual experiences within the wider context in which they occur and are negotiated, particularly social networks, the neighbourhood and the household. Third, the complex migration and acculturation processes experienced by the respondents are sketched through the use of different qualitative methods; by situating the findings within surrounding contexts as well as by exploring the intersections of education, ethnicity and gender.

\section{Background}

\section{Moroccan Migration towards Spain and Madrid}

Spain is described as one of the so-called 'new countries of immigration', as high immigration levels only started in the 1980s, in contrast to North-Western European countries. According to data from the Ministry of Labour and Immigration (2011), the number of legal migrants in Spain (a country with 47 million inhabitants) was $5,144,269$ as of June 2011. The Moroccan community is the largest foreign community (822,997 persons) and had the second biggest numerical increase in 2007, after the Romanians (Ministerio de Trabajo e Inmigración, 2011). Most people in the Moroccan community are adults, but we can already discern a significant increase of the second generation, with over 100,000 persons. Within Spain, Moroccans are principally established in Catalonia, Andalusia, the Region of Madrid and the Valencia Region (see figure 1). In Catalonia and the regions of Madrid and Valencia,

* Netherlands Interdisciplinary Demographic Institute (NIDI) / KNAW / UG. mol@nidi.nl 
Moroccans mainly live in the major cities, whereas in Andalusia, they are more dispersed. The reason for this dispersion can be found in the characteristics of the Andalusian economy. Agriculture is still very important in the southern region of Spain, while in Madrid the care and construction sector are more important.

\section{INSERT FIGURE 1 ABOUT HERE.}

Initially, Moroccan migration to Spain was mainly a labour flow, principally dominated by male workers who came on their own for seasonal work. However, in the early 1970s, the oil crisis precipitated an economic recession and European governments closed borders and increased entry restrictions for migrants. The new channels for entry became family reunification and asylum. For this reason, the seventies can be seen as the beginning of Moroccan female migration: the women primarily immigrated for family reunification reasons (López García, 2004a; Ramírez, 2004). At the end of the 1980s, Moroccan women started to participate individually in the migratory processes to Spain, coming independently as workers and thereby modifying the initial Moroccan migratory model (López García, 2004a; Ramírez, 2004). This process occurred in conjunction with an internal female migration within Morocco. Industries in big cities such as Casablanca, Tangiers and Fez drew women workers from less economically developed and rural regions of the country. During

* Netherlands Interdisciplinary Demographic Institute (NIDI) / KNAW / UG. mol@nidi.nl 
the 1990s, many Moroccan women in the Spanish care sector and catering industry consisted of female migrants with an independent migration project (Gómez Crespo, 2004), however, a considerable share of these women tended to be married and had children, and therefore utilised family reunification as a method of migration. This led to an inverse family reunification model, with the women taking the initiative to regroup with their families, as opposed to the men doing so.

Nevertheless, according to the aforementioned report of the Spanish Ministry of Labour and Immigration (2011), the majority of the Moroccan community in Spain is still male (486,924 to 321,709 women). Ribas Mateos et al. (2000) described the increased presence of Moroccan women as a feminisation of the migration stream, even though other immigrants, for example those from the Dominican Republic, have always been primarily women (Cachón Rodríguez, 2007). It is important to note, though, that the gender dynamics among Moroccan economic migrants can be very different from those who arrive in Spain to study and those who possess resident permits. According to other statistics of the Spanish Ministry of Labour and Migration (2008), the numbers of female and male students are almost equal (1,462 Moroccan male students versus 1,216 female students). Women are progressively gaining access to university education in Morocco, especially in the cities, and some of these individuals also seek academic opportunities abroad. In fact, overall, there has been a gradual increase in the educational level of young women emigrating from Morocco

* Netherlands Interdisciplinary Demographic Institute (NIDI) / KNAW / UG. mol@nidi.nl 
since the 1990s (García et al., 2004). However, the feminisation of the Moroccan community is not equal among all Spanish autonomous regions: women who arrive independently mainly concentrate in the Region of Madrid (López García, 2004).

The attraction of Spain for Moroccans can be explained by a variety of variables, such as the opportunity to find work (even though with the current economic crisis work may be harder to acquire), familiarity with the Spanish language because of the historical connection between the two countries, the existence of social networks, the availability of better living conditions, and the positive juridical status of migrants (Soriano Miras, 2006). This juridical status is defined in Spanish Immigration Law: Moroccan citizens need a visa to enter Spain. The most common residence visa are granted for employment $(80,516)$ or family reunification $(62,288)$ (Ministerio de Trabajo e Inmigración, 2011). Moroccan women are able to join their husband if he has lived in Spain for at least one year legally, and if he possesses a residence permit for at least one additional year. Moreover, the husband has to prove the familial links, as well as possess an adequate living place and enough financial means to support the family. The duration of a woman's residence permit is initially linked to the permit of her husband, however, she can apply for an independent residence permit once she has a stable job, or sufficient economic means to sustain herself. The focus of this article is on Moroccan women who migrated to join their husband in Spain.

* Netherlands Interdisciplinary Demographic Institute (NIDI) / KNAW / UG. mol@nidi.nl 


\section{Acculturation processes of migrant women}

In Anthropology, the concept of acculturation is considered a useful theoretical tool for studying and interpreting processes of cultural contacts and their outcomes (e.g. Bastide, 1960; Herskovits, 1938). Acculturation refers to the cultural changes that migrants experience when settling in a new country. With culture, I refer to a 'system of shared beliefs, values, customs, behaviours and artifacts that the members of a society use to cope with their world and with one another, and that are transmitted from generation to generation through learning' (Bates and Plog, 1990: 7). Whereas early scholars often focused on cultural contact between groups, the individual inventiveness and agency of individuals has been highlighted in later works (Leal, 2011; Teske and Nelson, 1974). Indeed, acculturation can occur simultaneously at the individual and the group levels (Spiro, 1955; Teske and Nelson, 1974). In this paper, I adopt an individual-level approach, investigating individual acculturation experiences as expressed by Moroccan women themselves. After all, since acculturation processes likely differ individually according to a plurality of factors, such as their socioeconomic status, their family situation, their region of origin and arrival, and their migratory trajectory, it is impossible to talk about 'Moroccan women' and 'Moroccan women's acculturation strategies' in general terms.

* Netherlands Interdisciplinary Demographic Institute (NIDI) / KNAW / UG. mol@nidi.nl 
To explain the heterogeneity in trajectories and experiences of Moroccan women, I rely on ecological systems theory (Bronfenbrenner, 1979), which situates individuals in different environmental systems, as well as an intersectional approach (Mc Call, 2005). After all, for a better understanding of individually experienced acculturation processes, these experiences should be situated within the wider contexts wherein they occur, as well as at the intersections of different social categories such as class, education, ethnicity and gender. Therefore, I investigate how these Moroccan womens' experiences are simultaneously restricted and enabled by their specific contexts. To grasp contextual influences on individual experiences, I focus on what is considered the micro-system in ecological systems theory, namely the relationships and interactions of an individual with the immediate environment. In this case, that means the neighbourhood, social networks and the women's family. The possibilities of establishing meaningful contact with the native population might, for example, be restricted because of ethnic segregation within cities or disapproval of such contact by the co-ethnic community and/or family (Martinovic et al., 2011). Individual acculturation processes are hence considered to be influenced - but not determined - by broader environments.

Lastly, whereas it is inadequate to explain women's acculturation experiences from the single perspectives of ethnicity and/or gender, an intersectional approach allows to go beyond 'single-axis frameworks' prioritising gender or race/ethnicity

* Netherlands Interdisciplinary Demographic Institute (NIDI) / KNAW / UG. mol@nidi.nl 
(Nash, 2008). According to Brah and Phoenix (2004: 76), intersectionality signifies 'the complex, irreducible, varied, and variable effects which ensue(s) when multiple axes of differentiation - economic, political, cultural, psychic, subjective and experimental - intersect in historically specific contexts'. At the individual level, an intersectional approach thus aims to contextualise intersectional subject positions, uncovering the underlying dynamics and multidimensionality of individual experiences at specific moments in time (Heyse, 2010). The intersectional framework hence allows us to explain variations in individual experiences among the group of Moroccan women and helps to understand the plurality of trajectories and coping mechanisms.

\section{Methodology}

This article is based on an exploratory qualitative study, which aimed to map the situation of Moroccan women in Madrid, and was conducted for the International Organization for Migration between March and July 2008. The paper is based on the qualitative section of the research project, consisting of 11 semi-structured in-depth interviews with Moroccan women, as well as the method of unobtrusive observation. The interviewed women were all between 19 and 55 years old. We initially located respondents through migrant associations and key informants. Thereafter, the snowball method was used to identify the remaining participants. All interviews were

* Netherlands Interdisciplinary Demographic Institute (NIDI) / KNAW / UG. mol@nidi.nl 
conducted in Arabic, French and/or Spanish, depending on the preference of the respondent. All interviewed women lived in (larger) cities in Morocco before migration (Fez, Larache, Ksar-el-Kebir, Nador, Tangier and Tetouan), and came to Spain to join their husbands. Furthermore, all but two of the interviewed women had completed higher education in Morocco.

The most difficult women to reach were those with relatively limited contacts outside of their ethnic communities. Therefore, we opted for unobtrusive observation, teaching a Spanish language course for three months to a group of Moroccan women of this type. Fifteen women attended the classes, which were taught once a week, and lasted approximately three hours. The anonymity of all observed subjects has been kept strictly confidential (all names mentioned in this article are fictitious). These women also came from larger Moroccan cities such as Meknes and Oujda. Nevertheless, their educational profile was very different from the interviewed women. Among these participants, there was only one women who had completed secondary education.

There were other methodological challenges to overcome, such as my status as a European, non-Muslim and male. A huge debate on the insider and outsider statuses in social sciences research has already been going on for several decades (see for example Van Mol et al. 2014), and it is not my aim to enter this debate. Nevertheless, I observed that my outsider status was an advantage for using the method of

* Netherlands Interdisciplinary Demographic Institute (NIDI) / KNAW / UG. mol@nidi.nl 
unobtrusive observation. Even though gender-differences are often considered significant barriers in fieldwork situations, my role as male European and nonMuslim, with some knowledge of the Moroccan language, was important to be accepted as a teacher by these women, as I was not considered a potential threat to the honour of their community or family. In contrast, my Muslim colleague was not allowed by the community to teach Spanish classes to the women. In sum, although it is often argued that gender and ethnic background might have a decisive influence on fieldwork relationships, there are other dimensions that define the researcher's position and the information he/she has access to, such as 'the time and place of the research; the power relationships within which the researcher and the researched coexist, the personalities and specific informants; and even the precise topic under discussion’ (Mercer, $2007: 4)$.

The combination of these qualitative methods permits a detailed description of the migration and acculturation processes of Moroccan women in Madrid, although it is important to bear in mind that the results cannot be extrapolated to all Moroccan immigrant women, as a large variety of migration motivations as well as opinions on their origin and host society, their traditions, gender roles, etc. could be observed even among the interviewed women. Whereas some women stated that they had migrated to Spain because their husbands lived there (particularly those women following the Spanish language course), other women indicated they were 'pushed' by the lack of

* Netherlands Interdisciplinary Demographic Institute (NIDI) / KNAW / UG. mol@nidi.nl 
job opportunities in Morocco (e.g. Safiya, 21 years old, Tetouan), or limited social rights in Morocco (e.g. Milouda, 30, Nador). Other women indicated that they wanted to provide their children with more educational opportunities (e.g. Meryem, 45, Larache). Whereas it is not the aim of this paper to explore retrospective migration motivations, this diverse set of motivations for joining their husbands in Spain already illustrates the active role migrant women play in the migration process.

\section{The role of social networks}

Today, social network theory occupies a prominent place within scientific migration literature (e.g. Massey, 1999). Also in our project, the interviewed women indicated that networks of relatives and friends influenced the location of their actual living place and formed an important source of support during the migration and acculturation process.

Most of the interviewed women possessed contacts apart from their husband before moving to Spain. These co-national contacts proved to be very useful for accessing a variety of functions that are also documented in other studies: information, work, housing, a language they can express themselves in, access to social relations, and a sense of security (e.g. Cook et al., 2011; Gill and Bialski, 2011; Ramírez, 1998). Fátima, a 34-year-old woman from Fez, for example, indicated that her brothers, who already lived in Madrid, provided her an extra support link during

* Netherlands Interdisciplinary Demographic Institute (NIDI) / KNAW / UG. mol@nidi.nl 
the first months in the Spanish capital. Moreover, after a while she separated from her husband because of matrimonial problems. She reported that not being dependent (solely) on her husband helped her to recover relatively quickly from the separation.

Nevertheless, the disposal and formation of co-national supportive networks can also have a reverse side: several women reported that such networks hamper contact with the local Spanish population, contact which is often desired by these women for a variety of reasons. Safiya's story illustrates this point. Safiya is a 21year-old woman from Tétouan, and has an older brother living in Madrid. Through such pre-existing social contacts, she was immediately incorporated in the Moroccan community, and found work quite easily through her ethnic network. Nevertheless, she expressed difficulties in socialising with the local Spanish youth. Interestingly, the intersection of ethnicity and education appears to mediate the degree to which the interviewed women rely on co-ethnic social networks. Safiya, for example, did not finish secondary education and appears to rely much more on Moroccan ethnic networks for finding work compared to the interviewed women disposing of a higher education degree. Finally, social networks also show to be interlaced with the specific neighbourhoods the women live in. This connection is explored in the next section.

\section{The ethnic composition of the neighbourhood}

* Netherlands Interdisciplinary Demographic Institute (NIDI) / KNAW / UG. mol@nidi.nl 
It has been reported that the spatial structure of a city influences the construction of predominant mono-cultural social networks (e.g. Amin, 2002; Vervoort, 2012). The interviewed women that lived in neighbourhoods predominantly inhabited by other migrants can indeed be considered to be excluded both spatially and socially from the mainstream Spanish society. In contrast, women living in more mixed or predominantly Spanish neighbourhoods reported more frequent contact with the local community. The specific location of an individual within Madrid hence influences the networks they have access to. A good illustration is the case of Salima, a 30-year-old woman from Nador. Initially, she lived in a neighbourhood in Saragossa, surrounded by newly-made Spanish friends. However, she divorced and moved to Madrid, where she expected to find more job opportunities. In the Spanish capital, she settled in a migrant neighbourhood, and at the time of the interview she noticed how different her social network looked. She had a lot of contact with co-nationals and members of other migrant communities, but interaction with the local Spanish population was rather scarce. Because she has children, she regularly meets Spanish people at the school entrance, but her contacts with them are brief, as everybody has to go off to work. These passing exchanges had not (yet) developed into more profound relationships. Such experiences were echoed during the interviews with other women living in such neighbourhoods. In such situations, 'mondialisation from below' (Portes, 1999) seems to take place: immigrants also form ethically heterogeneous

* Netherlands Interdisciplinary Demographic Institute (NIDI) / KNAW / UG. mol@nidi.nl 
social networks with supportive functions in their everyday surroundings. As a result, the specific spatial location of where migrant women live often influences their interaction patterns. Living in a migrant neighbourhood can provide the Moroccan women with support from their community, the development of family and neighbourhood networks, and the maintenance of their language and culture. Simultaneously, it potentially limits their interaction with the local population.

In addition, I explored whether any pattern could be detected regarding the educational background of the respondents. Women with a higher education degree appear to be more likely to settle in more mixed or Spanish-dominated neighbourhoods. Nevertheless, as the story above of Salima, the woman from Nador, illustrates, this initial situation is not irreversible. Subsequent internal moves within Spain or within the city of Madrid might land these women in neighbourhoods where more co-nationals live, or conversely direct them towards mixed or Spanishdominated neighbourhoods.

\section{The impact of social networks and neighbourhoods on acculturation}

The spatial situation of Moroccan women and the related social networks have an influence on different domains of their life. As Gupta and Ferguson (1997) stated, locations also determine identities. For that reason, the degree of contact with the local community, other immigrant communities and their ethnic community is

* Netherlands Interdisciplinary Demographic Institute (NIDI) / KNAW / UG. mol@nidi.nl 
important in restructuring these women's identities. It seems that Moroccan women with regular contact with the Spanish population enter the 'acculturative arena' (Pels and De Haan, 2007) rather quickly; a diversity of contexts and relations which demand both the search for the best balance between continuity and change, and also constant adaptations to the new situations. The interviewed women who lived in mixed neighbourhoods reported having frequent contact with the Spanish population and incorporating certain aspects of Spanish life in their daily lives. There is the example of Layla, a 46-year-old Moroccan journalist: she works long days until 8 or 9 at night, and has a lot of contact with the Spanish population through her job. She agrees that the contact with the local population she has in her working life are important for getting to know Spanish society. Nevertheless, it should be noted that the establishment of such contact was not as straightforward as it appears at first glance. Although Layla obtained a higher education degree in Morocco and a stable job related to her studies, she experienced job downgrading upon arrival in Spain. As she was unable to secure a job matching her expertise in Madrid, Layla worked as a social worker for several years, supporting Moroccan immigrants. Her networks in Spain hence comprised many co-national contacts before moving into a job dominated by Spanish contacts.

Women who live more segregated from Spanish society, moving mainly within predominantly mono-cultural environments, however, seem to be less exposed

* Netherlands Interdisciplinary Demographic Institute (NIDI) / KNAW / UG. mol@nidi.nl 
to other (local or migrant) cultures and, as a result, can experience a much slower acculturation process. The participants of the Spanish language course clearly illustrate this dynamic. The majority of the fifteen participating women lived more than five years in Spain, in a neighbourhood dominated by Moroccan immigrants, and they had limited Spanish speaking skills. As they were surrounded by co-nationals, they could easily survive without Spanish with the help of their children and husbands, and they rarely had contact with the local Spanish population. Furthermore, their educational profile might play a role as well. Among these women, only one had completed secondary education. The absence of educational qualifications and the lack of Spanish language skills makes it difficult or perhaps impossible to participate in the Spanish labour market and/or interact with natives at work or school gates. This does not mean, however, that they do not experience changes at all. Group talks with them during the Spanish language classes revealed that the minimal contact they have with Spanish society - for example going to a grocery store, or collecting their children from school - still has an influence on their identity and habits. Within the immigration context, their children and husbands are exposed every day to Spanish society at school and at work, bringing the new society and culture also into the living place. Although these women seemed to emphasise and adhere more tenaciously to the importance of maintaining Moroccan culture compared to the women that did not live in this separated community, they also incorporate changes into their daily lives,

* Netherlands Interdisciplinary Demographic Institute (NIDI) / KNAW / UG. mol@nidi.nl 
which are the result of the migratory situation and direct or indirect exposure to

Spanish society - through, for example, their children or husband. For example, some women admitted to having incorporated Spanish dishes - such as tortilla - into their cuisine.

\section{Acculturation processes within the household}

Logically, the dynamics of the studied Moroccan families change during the migration and acculturation process. Women gain more autonomy vis-à-vis other members of the family, especially when they arrive as independent immigrants and are reasonably fluent in Spanish. They play an active role of transmitters of change within their respective families.

Although most of the interviewed women hinted at an intention to change their family relationships in some respects, they simultaneously aim to maintain close ties with their native culture and have a definite aim to transmit this culture to their offspring. Moroccan women particularly emphasised the conservation and maintenance of their own language, religion, and the traditions they consider typical expressions of their culture such as - for some of them - wearing the veil. Furthermore, some of the interviewed women as well as all the women attending the language course indicated certain traditional gender and family roles to be typical for their culture, and were very keen to hold on to them. As an example, in Moroccan

* Netherlands Interdisciplinary Demographic Institute (NIDI) / KNAW / UG. $\underline{\text { mol@nidi.nl }}$ 
(and Islamic) culture, men are often responsible for providing financial sustenance for the family, and women for educating the children. This scheme did not always change in the families of our respondents. Some women stated that the most important task for men is to earn money; for example, Fátima explained that "the man has to be in charge of all material issues". She argued that while it is an obligation for men, for women it is a choice. In addition, the realm of children's' education was considered uniquely women's responsibility by many of the respondents. However, the intersection with educational as well as familial background is interesting. Changes in gender roles are not only the result of the migration trajectory and acculturation processes, but were for some of the women already enhanced in Morocco before migration. Layla, the 46-year old journalist, for example, reported to originate from a progressive family in the city of Tangiers. Her parents strongly encouraged her to go to university, and she reacted against the idea of staying at home to take care of the children and the household during the interview. Similar accounts were given by other highly educated women as well. Nevertheless, regardless of their education, all women showed resistance towards a complete assimilation to Spanish culture.

Change and continuity thus go hand in hand; the women referred, for example, to positive changes in gender relations after migration, with men being more helpful with household chores, while simultaneously expressing the wish to maintain some traditional gender roles. The wide cross-section of Moroccan women profiles

* Netherlands Interdisciplinary Demographic Institute (NIDI) / KNAW / UG. mol@nidi.nl 
should, again, be kept in mind. Various authors argue that migration reorganises gender relations (e.g. Hondagneu-Sotelo, 1992). However, in some contexts, this reorganisation is much less salient than others. Once again, the women attending the Spanish classes are a good example. They all stated they came to Spain because their husband lived there, they all had limited formal education (several of them were illiterate), and they all lived in an ethnically homogenous neighbourhood. Compared to women with a higher education degree and/or different migratory motivations (see the methodological section), they seemed to wish to preserve traditional gender relations and roles to a larger extent. Most of these women tended to be less tolerant towards women who choose not to wear their veil, and repeatedly stressed the importance of strictly following the Koran. In contrast, women living in more mixed neighbourhoods and with regular contact with the local population or other migrant communities mainly argued that everybody should have the choice whether to wear the veil or not. Moreover, these women also argue for a more dynamic interpretation of religion, referring to the Koran to show that wearing the veil was never obligated by the prophet Mohammed. Finally, these women also made a clear separation between religion in private and public life. Or as Layla stated: "I am Muslim for myself, in my daily acts. In my work life, in everyday life, I am secular”.

In contrast, the vertical transmission of culture - purposeful transmissions between generations within a family - shows to be essential for all women regardless

* Netherlands Interdisciplinary Demographic Institute (NIDI) / KNAW / UG. mol@nidi.nl 
of their education. Such transmissions, however, are often challenging, as the dominant society may reinforce social norms that differ from ethnic ones. All women emphasised the importance of passing on the Moroccan language and maintaining Moroccan culture within the family, as the following citation shows:

I want our children to have links with our original culture; in fact the children are going to Morocco mainly to study Arabic. They studied, not much, but at least we can understand them when they talk and they can write a little bit. And now they are at a very interesting age; I think this reinforcement of the links with the country of origin has had some results. They are playing with the culture from here and there. (Layla, 46 years)

This quote illustrates that the wish for cultural continuity does not necessarily exclude cultural change. The fact that their children combine elements of two cultures is positively interpreted, and illustrates the experienced acculturation process.

\section{The transversal role of language throughout the acculturation process}

Throughout the interviews and qualitative fieldwork, language learning and apprehension were revealed as playing an important role for Moroccan women throughout their integration process into Spanish society. Learning the host country

* Netherlands Interdisciplinary Demographic Institute (NIDI) / KNAW / UG. mol@nidi.nl 
language is essential in a migratory context, bearing in mind that women may lose their influence in the direct environment after migration when they do not have sufficient linguistic skills (Nyhagen-Predelli, 2004). Moroccan women who form part of the labour market particularly seem to consider fluency in Spanish fundamental as a key requirement for working and integrating into Madrid. Women who are not able to express themselves in Spanish expressed becoming more dependent on their husbands and children for their contacts with the host society, as for example with their children's school administration; they also often face difficulties in finding a job. Stories such as the one of Naima (42 years), one of the women attending the classes, who has a work permit, but cannot find a job because she does not speak Spanish, are not exceptional cases. Linguistic fluency seems to be an essential element for finding a job in Madrid, even more so since the increase in Latin-American female migration. Latin-American women are generally native speakers, which gives them a competitive advantage for finding work, particularly in the care and catering sector.

The language learning process also has consequences on other spheres of Moroccan women's life in Madrid. When they learn the language, this sometimes leads to changing gender roles in the family. Rabeia, a 33-year-old women from Fez, for example, stated that she easily found work because of her knowledge of Spanish. This is in sharp contrast with her husband, as he is always working with other Moroccan immigrants. Even though she depended on her husband for coming to 
Spain through the family reunification procedure, he now depends increasingly on her and her command of Spanish for organising their daily life.

However, there are numerous obstacles to learning Spanish. Even though there are signs of progress, illiteracy is still high among women in Morocco: it has been reported that 45.1 per cent of urban and 84.2 per cent of rural women are still illiterate today (Desrues and Moreno Nieto, 2009). In the Spanish language course, the illiterate women faced more difficulties in learning Spanish than the other students, as they had to learn to read and write simultaneously. In addition, their children often speak better Spanish than they do. Although this could lead to the children seriously questioning the parents' authority (Pels and De Haan, 2007), this was not reported by our interviewees. They are all very proud that their children were able to learn the new language so quickly. Moreover, they consider the contact of their offspring with Spanish children essential for their societal integration. Television plays a role in learning the language, but most respondents said that they become bored with Spanish television and they prefer Arab channels accessed through paid television. As one of the women explained:

The satellite is bad [so even though] I did not know the language, I watched Spanish television. I did not understand anything, I just watched. Four years ago I bought a satellite, days and nights Arab, Arab, Arab television. And the

* Netherlands Interdisciplinary Demographic Institute (NIDI) / KNAW / UG. mol@nidi.nl 
children also. And now the children, the eldest has a problem with Spanish. (Latifa, 31 years)

The residential model in establishing social networks with the local and immigrant population seems to be an important factor in the apprehension of Spanish, as well. The interviewed women who live in Spanish or ethnically heterogeneous neighbourhoods seemed to have a better knowledge of the language than women who live in mono-cultural areas. Nevertheless, migrant women who live in such segregated areas, but are in regular contact with the local population, for example through their work, generally also have a good knowledge of the language. In our study, Moroccans who spoke the language fluently seemed to be more favourably inclined towards the Spanish lifestyle than the women who did not. Since they are able to communicate with their direct environment, and are more exposed to Spanish ideas, culture and values, they emphasise less the importance of a strong maintenance of their own culture. However, this does not mean that these women do not orient themselves towards Morocco anymore.

\section{A new transnational lifestyle}

The acculturation processes in Spanish society thus lead to changes in Moroccan women's lives. The change of socialisation patterns does not go unnoticed in Morocco

* Netherlands Interdisciplinary Demographic Institute (NIDI) / KNAW / UG. mol@nidi.nl 
thanks to frequent transnational contacts and the influence of the Internet as a means of communication (Pels and De Haan, 2007). The Moroccan female migrants of our study considered it extremely important to preserve family relationships in their country of origin. Although the role of the women might change during the migration process and physical contact with the extended family in the country of origin gradually diminishes, the family does not lose its importance. As Fátima, for example, narrated: "I have a strong relationship with my family. The family here is not the same as in Morocco. There, my brothers, parents, nephews, aunts all form part of the family, you know?" Most interviewed women reported plans to return to Morocco in the summer and to preserve the desire to return definitively one day. However, this dream seems more difficult to realise when children are born in Spain. Most women choose to educate and school their children in Spain, and argue that there are more opportunities for their children if they acquire an adequate education level:

For my daughter it is better not to return, she has to study, grow up here, because there is a future for her, in Morocco there is no future, the work is bad and studies also. (Rabeia, 33 years)

Similar statements were made by several women, regardless of the gender of the respective child(ren).

* Netherlands Interdisciplinary Demographic Institute (NIDI) / KNAW / UG. mol@nidi.nl 
It can be observed that the interviewed women show an affinity with Spain, because of their social relationships and affinities in the country. At the same time, they identify themselves as Moroccans due to their relations with the country of origin and the maintenance of cultural practices, particularly in the private sphere. In this way, they build a transnational lifestyle. This double identification is also the origin of a process of rupture and discontinuity between their life in Morocco and their life in Madrid (Salih, 2003 : 79). Parallel to the maintenance of their links with Morocco, women thus paradoxically raise the need to redefine their territory in a dialectical relation with the wish to be transnational and the affirmation of their belonging to two countries simultaneously (Salih, $2003: 79)$.

\section{Conclusion}

In this paper, I aimed to provide rich and nuanced insight into individual migration and acculturation experiences of Moroccan women in Madrid, situating these experiences within broader surrounding contexts. I particularly showed that Moroccan women pass through complex acculturation processes that orient them within both the society of origin and that of arrival. The changes they experience are characterised by a constant negotiation between learning the tradition of the locals, the reorientation of their Moroccan traditions and the invention of new solutions which are reformulations of these elements. As such, Moroccan women in Madrid construct a new cultural

* Netherlands Interdisciplinary Demographic Institute (NIDI) / KNAW / UG. $\underline{\text { mol@nidi.nl }}$ 
plurality, which incorporates elements of various cultural systems. This acculturation process is not always easy for them, but they develop clear strategies to overcome the obstacles on their way. The best description might be one provided by the Moroccan women themselves. Nawal (46 years old) phrased it the following way: "For me it was not a shock, it was just a joining of experiences that I had to overcome day by day".

The presented results illustrate that individual acculturation experiences of Moroccan women are highly diverse. Instead of considering them as mere followers of their husbands, it is more fruitful to consider them as active agents, making independent decisions. Although officially they all came to Spain to join their husbands, their personal migration motives are highly diverse, and do not always correspond to their 'official' status. Furthermore, specific migration and acculturation experiences are situated at the intersection of education, ethnicity, familial background and gender, as well as influenced by the surrounding contexts wherein these experiences take place. I showed, for example, that social networks provide the women with support and orientation for their adjustment to the new context. However, together with the residential segregation in certain districts of the Madrid metropolitan area, mono-cultural social networks can initially slow down women's acculturation processes. In addition, the presented analysis shows how access to different networks as well as the spatial distribution across different neighbourhoods

* Netherlands Interdisciplinary Demographic Institute (NIDI) / KNAW / UG. mol@nidi.nl 
appears to be influenced by the educational background of the respondents. The more highly educated women are, the more possibilities they seem to enjoy for establishing contact with members of the majority society. Nonetheless, through direct and indirect exposure, low-educated Moroccan women living in homogeneous and segregated communities slowly emerged into complex acculturation processes as well.

At the household level, the interviewed women actively negotiate the balance between elements of both societies. Although they incorporate elements of Spanish culture within their daily life, this does not mean they totally discard Moroccan culture. Although considerable variation exists, all women emphasised the need to maintain certain elements of Moroccan culture, particularly in terms of customs, language and religion in relation to the intergenerational transmission of culture. This reveals the complex nature of their acculturation process. Migrant women move in a transnational space with rigid borders, which allows them to participate simultaneously in two societies and cultures. This transnational space, furthermore, is intersected by several social categories such as their education, ethnicity and gender, which influence their relative position within this space.

In conclusion, in this paper I explored acculturation as an individual process. I highlighted how individual acculturation processes are situated at the intersections of education, gender and ethnicity. Furthermore, it is clear that for a more holistic understanding of individual acculturation experiences, the contextual embeddedness

* Netherlands Interdisciplinary Demographic Institute (NIDI) / KNAW / UG. mol@nidi.nl 
of these experiences should not be overlooked. As a final note, it is worth mentioning that this project was limited in time and scope. This paper focused on a particular group of migrant woman, namely Moroccan women who came to Spain for family reunification. Consequently, it remains debatable whether the presented results can be extrapolated to a broader group of Moroccan women, migrant women from other nationalities, and/or other national contexts. Furthermore, I only highlighted the experiences and viewpoints of Moroccan women. Nevertheless, acculturation processes are most likely also influenced by the attitudes and opinions of the local population towards migrants, which might be influenced, for example, by perceived cultural, ethnic and/or religious differences. Future research comparing and contrasting the narratives of the local population with those of migrants might thus significantly advance our understanding of acculturation processes. Undoubtedly, we need more in-depth research on gendered acculturation processes for a better understanding of the dialectical relation that exists in a migration context between the society of origin and the one of arrival.

\section{Acknowledgments}

This article is based on a study conducted at the International Organization for Migration (IOM) in Madrid in 2008, in the framework of my Master's thesis for the International Master in Migration Studies at the Universitat de València. I would like

* Netherlands Interdisciplinary Demographic Institute (NIDI) / KNAW / UG. mol@nidi.nl 
to thank Kouider Djilali Beloufa for his collaboration in the data collection process.

Furthermore, Noel Clycq, Giusella Latorre, Paul Spickard and Judy Wu as well as the anonymous reviewers provided helpful comments and suggestions. Finally, thanks to Mary Graham for proofing the paper.

\section{References}

Amin A (2002) Ethnicity and the multicultural city: living with diversity.

Environment and Planning A 34(6): 959-980.

Bastide R (1960) Les Religions Africaines au Brésil. Paris: Presses Universitaires de France.

Bates DG and Plog F (1990) Cultural Anthropology. New York: McGraw-Hill.

Brah A and Phoenix A (2004) Ain't I a woman? Revisiting intersectionality. Journal of international women's studies 5(3): 75-87.

Bronfenbrenner U (1979) The ecology of human development: Experiments by nature and design. Cambridge: Harvard University Press.

Cachón Rodríguez L (2007) Diez notas sobre la inmigración en España 2006. La Vanguardia 22: 68-74.

Cook J, Dwyer P and Waite L (2011) 'Good Relations' among Neighbours and Workmates? The Everyday Encounters of Accession 8 Migrants and

* Netherlands Interdisciplinary Demographic Institute (NIDI) / KNAW / UG. mol@nidi.nl 
Established Communities in Urban England. Population, Space, and Place 17(6): 727-741.

Desrues T and Moreno Nieto J (2009) The development of gender equality for Moroccan women - illusion or reality? Journal of Gender Studies 18(1): 2534.

Díe L, Buades J, Melero L, et al. (2009) Nuevos ciudadanos de Marruecos en España. Los contrastes vistos desde la diáspora. Valencia: Fundación Ceimigra.

García C, Alcalde R, Moreno R, et al. (2004) Las mujeres marroquíes en Cataluña: entre la trasgresión y el cambio. Revista Catalana de Sociología 18: 27-44.

Gill N and Bialski P (2011) New friends in new places: Network formation during the migration process among Poles in the UK. Geoforum 42(2): 241-249.

Gómez Crespo P (2004) El proceso de reagrupación familiar. In: López García B and Berriane M (eds) Atlas de la inmigración marroquí en España. Madrid: Universidad Autónoma de Madrid, pp.226-227.

Gupta A and Ferguson J (1997) Culture, power, place: Ethnography at the End of an Era. In: Gupta A and Ferguson J (eds) Culture, power, place. Explorations in Critical Anthropology. Durham \& London: Duke University Press, pp.1-29. Herskovits MJ (1938) Acculturation. The study of culture contact. New York: J.J. Augustin Publisher.

* Netherlands Interdisciplinary Demographic Institute (NIDI) / KNAW / UG. mol@nidi.nl 
Heyse P (2010) Deconstructing Fixed Identities: An Intersectional Analysis of

Russian-speaking Female Marriage Migrants' Self-representations. Journal of Intercultural Studies 31(1): 65-80.

Hondagneu-Sotelo P (1992) Overcoming Patriarchal constraints: The Reconstruction of Gender Relations Among Mexican Immigrant Women and Men. Gender \& Society 6(3): 393-415.

Joseph S (2000) Gendering Citizenship in the Middle East. In: Joseph S (ed) Gender and Citizenship in the Middle East. New York: Syracuse University Press, pp.4-30.

Leal J (2011) “The past is a foreign country?” Acculturation theory and the anthropology of globalization. Etnográfica 15(2): 313-336.

López García B (2004a) Desarrollo y pervivencia de las redes de origen el inmigración marroquí en España, Madrid: Universidad Autónoma de Madrid.

López García B (2004b) La periferización de los marroquíes en la Comunidad de Madrid. In: López García B and Berriane M (eds) Atlas de la inmigración marroquí en España. Madrid: Taller de Estudios Internacionales Mediterráneos, pp.347-348.

Martinovic B, van Tubergen F, Maas I 2011 Acquisition of Cross-Ethnic Friends by Recent Immigrants in Canada: A Longitudinal Approach. International Migration Review 45(2): 460-488.

* Netherlands Interdisciplinary Demographic Institute (NIDI) / KNAW / UG. mol@nidi.nl 
Massey DS (1999) Why Does Immigration Occur? A Theoretical Synthesis. In:

Hirschmann C, Kasinitz P and De Wind J (eds) The Handbook of International Migration: The American Experience. New York: Russell Sage Foundation Publications, pp.34-52.

McCall L (2005) The complexity of intersectionality. Signs, 30(3): 1771-1800.

Mercer J (2007) The challenges of insider research in educational institutions: wielding a double-edged sword and resolving delicate dilemmas. Oxford Review of Education 33(1): 1-17.

Ministerio de Trabajo e Inmigración (2008) Informe Trimestral 2/2008. Madrid: Ministerio de Trabajo e Inmigración.

Ministerio de Trabajo e Inmigración (2011) Informe Trimestral 2/2011. Madrid: Ministerio de Trabajo e Inmigración.

Morokvasic M (1984) Birds of passage are also women. International Migration Review 18(4): 886-904.

Nash JC (2008) Re-thinking intersectionality. Feminist Review 89(1): 1-15.

Nyhagen-Predelli L (2004) Interpreting Gender in Islam. A Case Study of Immigrant Muslim Women in Oslo, Norway. Gender \& Society 18(4): 473-493.

Pels T and De Haan M (2007) Socialization practices of Moroccan families after migration. A reconstruction in an 'acculturative arena'. Nordic Journal of Youth Research 15(1): 71-89.

* Netherlands Interdisciplinary Demographic Institute (NIDI) / KNAW / UG. mol@nidi.nl 
Portes A (1999) La mondialisation par le bas. L'émergence des communautés transnationales. Actes de la recherche en sciences sociales 129(1): 15-25.

Ramírez A (2004) Las mujeres marroquíes en España a lo largo de los noventa. In: López García B and Berriane M (eds) Atlas de la inmigración marroquí en España. Madrid: Taller de Estudios Internacionales Mediterráneos, pp.223225 .

Ramírez Á (1998) Migraciones, Género e Islam. Mujeres Marroquíes en España, Madrid: Agencia Española de Cooperación Internacional.

Ribas Mateos N (2000) Female Birds of Passage: Leaving and Settling in Spain. In: Anthias F and Lazaridis G (eds) Gender and Migration in Southern Europe. Women on the Move. Oxford \& New York: Berg, pp.173-198.

Salih R (2003) Gender in Transnationalism. Home, longing and belonging among Moroccan migrant women, London \& New York: Routledge.

Soriano Miras RM (2006) La inmigración feminina marroquí y su asentamiento en España. Un estudio desde la Grounded Theory. Revista Internacional de Sociología 64(4): 169-191.

Spiro, ME (1955) The acculturation of American Ethnic Groups. American Anthropologist 57(6): 1240-1252.

Teske RHC and Nelson BH (1974) Acculturation and assimilation: a clarification. American Ethnologist 1(2): 351-367.

* Netherlands Interdisciplinary Demographic Institute (NIDI) / KNAW / UG. mol@nidi.nl 
Van Mol C, Mahieu R, De Clerck HM, Piqueray E, Wauters J, Levrau F,

Vanderwaeren E, Michielsen J (2014). Conducting qualitative research:

Dancing a tango between insider- and outsiderness. In: Voloder L. \&

Kirpitchenko L. (eds.) Insider Research on Migration and Mobility.

International Perspectives on Researcher Positioning. Aldershot: Ashgate.

Vervoort M (2012) Ethnic Concentration in the Neighbourhood and Ethnic Minorities'

Social Integration: Weak and Strong Social Ties Examined. Urban Studies 49(4): 897-915.

* Netherlands Interdisciplinary Demographic Institute (NIDI) / KNAW / UG. mol@nidi.nl 
Figure 1: The Moroccan community in Spain

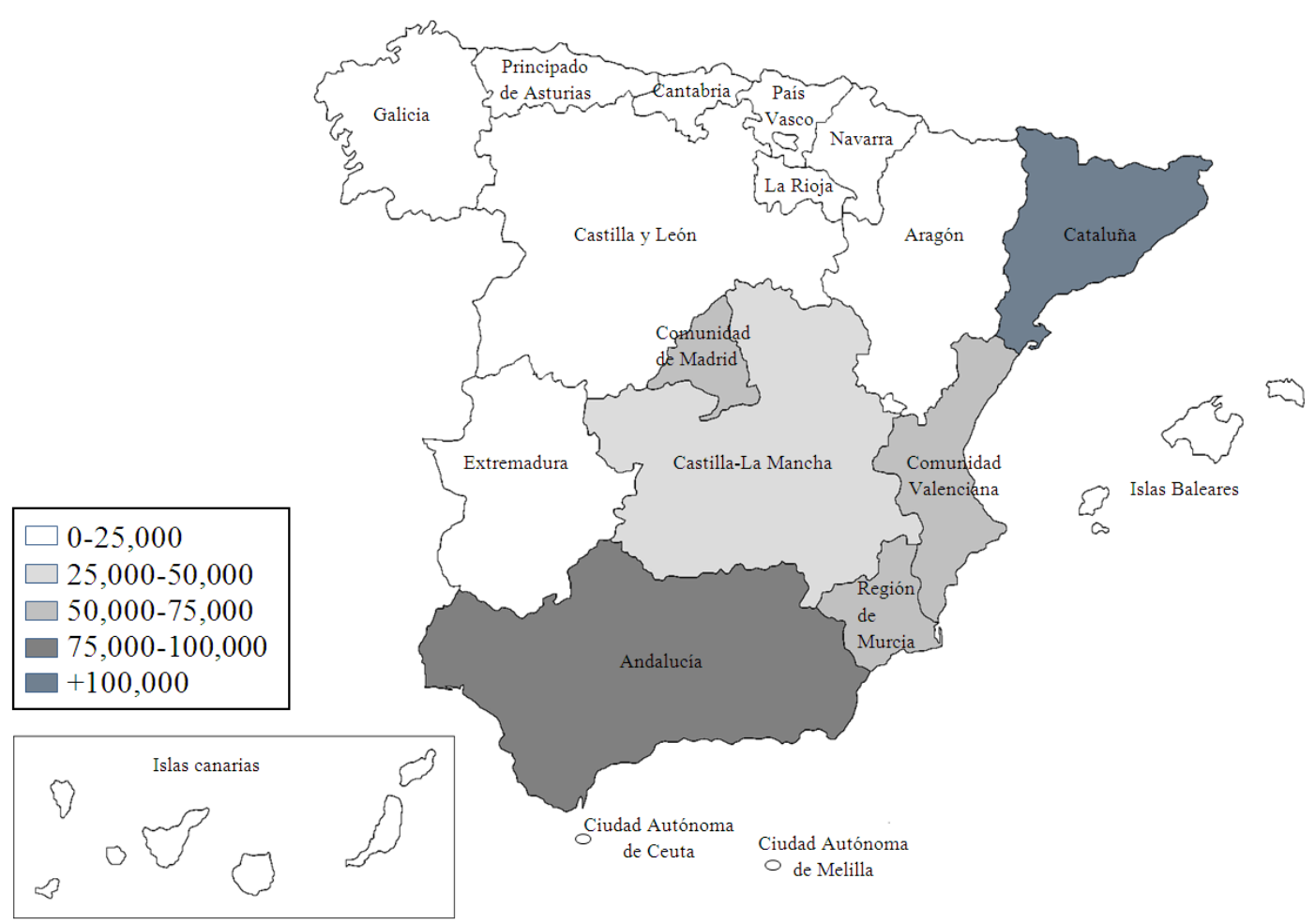

Source: Informe Ministerio de Trabajo e Inmigración, 1/2008

* Netherlands Interdisciplinary Demographic Institute (NIDI) / KNAW / UG. $\underline{\text { mol@nidi.nl }}$ 
CHRISTOF VAN MOL is Senior Researcher at the Netherlands Interdisciplinary Demographic Institute / KNAW / UG.

ADDRESS: Netherlands Interdisciplinary Demographic Institute (NIDI), Lange

Houtstraat 19, the Hague, 2511CV, the Netherlands. Email: mol@ nidi.nl

* Netherlands Interdisciplinary Demographic Institute (NIDI) / KNAW / UG. mol@nidi.nl 